\title{
Aljovín de Losada, C. \& Velázquez Castro, M. (compiladores) (2017). Las voces de la modernidad Perú, 1750-1870. Lima: Fondo Editorial del Congreso del Perú.
}

El libro analiza veinte conceptos fundamentales para entender la política moderna inaugurada desde su paso del imaginario virreinal al período republicano y que nos ayuda entender nuestros días. Hay una necesidad de distanciarse de una arqueología del significado del concepto, buscando más bien entender su evolución y cómo los sentidos de estas nociones mantienen su vitalidad en el imaginario político actual. Se trata de instrumentos para la reflexión y la acción, de comprender el imaginario político a través de conceptos utilizados por los actores históricos elaborados para describir y organizar su mundo.

Esto puede aplicarse a un período convulso en el que el imaginario republicano fue adquiriendo sentido conforme se asentaban los conceptos en el devenir temporal. Lo que se muestra es que hay una resignificación de conceptos de acuerdo con el contexto en que se produce. El objetivo es comprender el imaginario político y social de la modernidad política del Perú. De esta forma, se remarca la necesidad de ver los conceptos en relación con un espacio político y cultural amplio, que tenga en cuenta una perspectiva atlántica. Es importante evitar los anacronismos históricos y la preferencia de mirar desde el presente los hechos y actores del pasado.

Hay dos referentes fundamentales que inspiraron el libro, se trata de la perspectiva de Quentin Skinner y Reinhart Koselleck al trabajar la palabra y su relación con los imaginarios sociales. Los conceptos en un período determinado tienen un significado en muchos casos contrapuestos. La palabra se encuentra en disputa. El signo tiene un sentido en relación con su contexto, este puede cambiar de sentido, depende del actor o grupo político que lo utiliza. Entender el concepto nos permite visualizar la importancia en la construcción del lenguaje en la comunicación de las ideologías. 
El libro también nos revela una mirada multidisciplinaria en el estudio de la fuente y sus conceptos. Ello se evidencia en la participación de sus autores, que proceden de distintos campos de las humanidades, como la historia, la literatura y la filosofía.

Es importante diferenciar las palabras de los conceptos. Estos últimos son fundamentales para entender una época, tienen una naturaleza polisémica y en momentos de conflicto pueden tener varios significados, ya que son los actores quienes redefinen un concepto en función a sus intereses, ideologías y tradiciones. Dichos conceptos requieren una perspectiva diacrónica, entonces es pertinente una historia de los propios conceptos. Así entendemos que los conceptos no son naturales, ni inmutables y se encuentran constantemente definiéndose.

Un referente importante para el presente estudio es Koselleck, quien buscó entender los imaginarios políticos de Alemania de los siglos XVIII al XX a través de conceptos fundamentales de la modernidad. Se menciona que el autor introduce cuatro variables que se dan en la historia de los conceptos: democratización, politización, ideologización y temporalización.

En el Perú, la primera vez que se dio la primera variable fue mediante el decreto de la libertad de imprenta, del 10 de noviembre de 1810. La segunda corresponde a la segunda mitad del siglo XIX con la Constitución de 1856, donde se estableció el derecho de formar asociaciones, las cuales animaran el debate político. Las dos últimas variables se hacen evidentes cuando en los conceptos se da un proceso de abstracción que les brinda un significado vacío y ciego; su generalidad les permite adscribirles a significados diversos, como ocurre con el concepto de patria.

Muchas veces los conceptos pueden ser contradictorios, pueden darse miradas liberales o autoritarias — véase por ejemplo la definición de 'patria' y 'ciudadano'- Conceptos de 'libertad' o 'civilización' fueron motivo de disputa. A continuación me gustaría enfatizar la pertinencia y utilidad de algunos conceptos tratados en el libro y cómo se hicieron presentes en el imaginario 
peruano y latinoamericano a través del arte. En este caso sigo a José Murilo de Carvalho quien en La formación de las almas. El imaginario de la República en el Brasil (1997) hace uso de monedas, pinturas y caricaturas para mostrarnos cómo los brasileños definieron el concepto 'república'.

El concepto 'América' es abordado por Cristóbal Aljovín, quien destaca la figura del virrey Fernando de Abascal como un actor político importante cuando funda el regimiento de la Concordia española del Perú. Abascal buscó unir a los españoles y americanos para que disipen sus rivalidades y, siendo vasallos de un mismo soberano, compongan una nación con iguales intereses y obligaciones. Sin embargo, José Baquíjano y Carrillo evidencia en su discurso el malestar de los americanos causado por las políticas borbónicas. Vidaurre imaginó América unida a España como una sola entidad. Frente a la invasión napoleónica, América sí incorpora a la nación que puede subsistir a pesar de la sumisión del territorio peninsular. En el libro se menciona que el concepto 'América', durante el siglo XVIII, estuvo asociado a la pertenencia a una comunidad integrada por la monarquía. También se dice que en ese período prevalecía el término "las Américas". La fractura semántica de ambos conceptos está asociada a la concepción emancipadora; para Bernardo de Monteagudo, por ejemplo, España y América son entidades diferentes. En este contexto, la representación de América asociada al arte la vemos en la figura alegórica femenina con plumas, como se ve en el cuadro de Pedro José Figueroa, Bolívar con la América India (1819).

La noción de 'América' y 'americanos' como referencia a una identidad no conquistó los corazones o las instancias estatales o políticas después de la independencia. Así, se enfatiza que el discurso sobre América fue visto más en el campo diplomático conformen tomaban fuerza la construcción de los estados nacionales. Hubo ciertos momentos de unión panamericana tales como los congresos americanos, los intentos del general Flores de aliarse con la corona de España a fines de 1830 o los peligros de la guerra de 1866. En esas circunstancias se invocó una "América Unida" con un solo destino. Dos obras ejemplifican esta idea, una es el cuadro Unión Americana (1867) de Francisco 
Laso, donde América sentada y entronizada en un cetro de piedra con diseños del Perú Antiguo es acompañada de la Mariana francesa alada y la alegoría de las repúblicas americanas donde destaca México devorada por el águila que representa la invasión de Maximiliano de Austria. Otro monumento que expresa América unida es el Monumento del dos de mayo (1874) realizado por el arquitecto Edmond Guillaume y el escultor Leon Cugnot en donde aparece la representación alegórica de las cuatro naciones en conflicto, Ecuador, Perú, Bolivia y Chile que darían frente a la escuadra española en 1866.

El concepto ‘civilización’ escrito por Marcel Velázquez se rodea de un sentido más político y cultural. La libertad de imprenta, la prensa y la cultura de lo escrito son símbolos de la nueva civilización. Se entiende una Europa civilizadora con un pensamiento ilustrado y un proyecto liberal republicano que tiene una misión civilizadora.

La civilización se asocia a lo moderno a los progresos visibles en infraestructura puentes, trenes y caminos. La libertad de comercio y de industria constituye la fuente de la civilización. Se trata de un amplio campo donde se puede dilucidar la independencia política, el progreso, la instrucción pública, ciencias y nuevas tecnologías de la información.

La civilización puede definir conceptos antinómicos vistos en pares como 'superstición'/‘razón', ‘inmovilismo'/'progreso', ‘despotismo'/‘república’ y 'civilización'/‘barbarie'. En este último caso puedo mencionar el tópico de la cautiva, desarrollado por Laura Malosetti; se trata de la mujer raptada por el indio de la pampa y la cual termina siendo sujeto ajeno en ambos espacios. La mujer blanca al pasar del espacio civilizado al de barbarie pierde su estatus social y se encuentra estigmatizada. Estos tópicos se encuentran presentes en la plástica rioplatense en artistas como Raymon Monvoisin, Juan Maurico Rugendas, Juan Manuel Blanes y Ángel Della Valle.

El proyecto civilizador debe abarcar la sociedad en su conjunto — tanto el comercio, las artes y las ciencias - ; así se pensó el libro de Manuel Atanasio Fuentes, 
Lima: apuntes históricos, descriptivos, estadísticos y de costumbres (1867) donde se buscaba evidenciar el proyecto moderno alternando imágenes costumbristas con el repertorio de puentes, plazas y espacios ordenados en la ciudad. Esto se hizo más evidente en el álbum República Peruana 1900 (1898 y 1900) del fotógrafo chileno Fernando Garreaud, donde la narrativa visual apostaba por la representación del progreso material de las ciudades, privilegiando los aspectos civilizatorios. Así, se muestra que el concepto civilizador y la forma como se estructura a inicios del siglo XIX está presente en los albores del siguiente siglo.

Bartolomé Herrera, representante a mediados del siglo XIX del pensamiento político conservador, sostenía que la civilización en el Perú estaba vinculada al cristianismo y los hábitos de la cultura española. Refiere que la posición frente al salvaje tendría que ser paternal y sentirse movido a dominarlo e ilustrarlo. Sabemos que fue Herrera quien trajo dos monumentos en Lima que condensan los ideales republicanos y civilizados asociados a la herencia española. Nos referimos a la Estatua ecuestre de Simón Bolívar (1859) de Adamo Tadolini y el Monumento a Cristóbal Colón (1860) de Salvatore Revelli donde se muestra un Colón en actitud paternalista protegiendo a América representada como una india semidesnuda y con plumas.

La relación entre arte y civilización fue mencionada por el pintor Francisco Laso, quien nos dice que no hay pueblo civilizado en que las artes hayan tenido un gran desarrollo. Se llama la atención acerca de que las artes son fuente de riqueza de un país civilizado. Un cuadro del artista que evidencia la orfandad de las artes frente al Estado peruano es el Concierto o Canto llano (1855-1856) donde se muestra a un músico y un cantante. Cabe mencionar que el personaje alegórico del negro, en el boceto era la representación de un pintor. Las artes en un concierto cerrado y $\sin$ que nadie las pueda ver o escuchar constituyen una crítica certera al estado de orfandad que existe en el Perú.

La industria, el comercio, las artes y las ciencias son los ejes donde se puede notar el grado de civilización del país. En tal sentido es interesante analizar el cuadro El Perú Libre (1849-1850) realizado por Luis Montero, donde se 
representa las artes liberales y el caduceo del dios mercurio asociado al comercio, quienes acompañan la representación alegórica del Perú. Así mismo, la portada de la revista El Perú Ilustrado (1887-1892) pone al comercio, los barcos a vapor o el ferrocarril con claras referencias civilizatorias.

El concepto de 'patria', escrito por David Velásquez, refiere que durante el siglo XVIII estuvo asociado al lugar de origen de un individuo. También se empleó como una entidad territorial y jurídica, como fue el virreinato peruano. El concepto de 'patria' cambia y se resignifica en la Constitución liberal de 1812, donde evidencia una comunidad de españoles y americanos que componían la monarquía: la nación española.

Serían los libertadores quienes unirían los conceptos de 'independencia' y 'libertad' al de 'patria'. Entonces esta ofrecía un horizonte de felicidad y bien común. En la década de 1820, años de la guerra de la independencia, la voz 'patria' alcanzó su mayor densidad semántica para después tener una creciente abstracción. Este proceso no fue uniforme y 'patria' tendió a vincularse con el Estado peruano en desmedro de la comunitaria América. De ciudad o pueblo de origen pasamos asociar patria a la república. Se reserva el nombre de patria para la nación entera.

En la celebración del centenario de la independencia, el creciente hispanismo revitalizó el discurso de Bartolomé Herrera y se habló de madre patria relacionada con España, y sus hijas las naciones americanas que al crecer se habían independizado. Se debía agradecer a España que nos había legado religión, raza y costumbres. Los mismos tópicos que fueron destacados por Bartolomé Herrera a la hora de referirse al Perú y su vinculación con España. Esta mirada se evidencia en el parque universitario de Lima, donde se levantó en los años veinte del pasado siglo un monumento a Bartolomé Herrera realizado por el escultor español Gregorio Domingo. El hispanismo del gobierno de Augusto B. Leguía se manifestó en proponer un monumento a los caídos españoles en la guerra de la independencia y el dos de mayo previsto para realizarse en el Cementerio General o en una plaza pública de Lima. 
El concepto 'república' es escrito por Carmen McEvoy. La autora menciona que este aparecía citado en el Mercurio Peruano desde una mirada humanista y cívica de estirpe latina. Así estuvo asociado al saber ilustrado. Sin embargo, adquiere con la independencia un sentido fundacional, donde se definió como opuesto a la monarquía absoluta. También hubo miradas como las de Luna Pizarro que asoció la república con los valores católicos.

Existirían tres conceptos que definen la república: la libertad, la opinión pública y la ciudadanía. La república debía asentarse sobre las virtudes cívicas. En la década de 1830, el concepto de república irá distanciándose del optimismo y del horizonte utópico de los padres fundadores. La sociedad peruana constituida en república no debía ser lo mismo que la sociedad virreinal. En la década de 1850 se cristaliza en el Perú un vocabulario republicano que se nutre de los conceptos como virtud moral, ciudadanía, representación, trabajo y opinión pública. El orden constituiría el elemento fundamental de la república. No bastó la legitimidad republicana fundada en la ley.

Sin duda, un aporte significativo es reflexionar sobre la historia de los conceptos y las formas cómo los actores imaginaron la política y la sociedad durante el siglo XIX, un período de experimentación e innovación que sienta las bases de la República. Los conceptos nos permiten entender qué miradas tuvieron los sujetos cuando imaginaron y actuaron en política. Si bien podemos notar en el libro a los actores y los conceptos que legitiman y justifican su actuar, me llama la atención los conceptos que se encuentran ajenos al imaginario político, en donde se articula lo disidente o lo que no pertenece al orden establecido: los indios de la amazonía, lo negro y lo mestizo. Los autores refieren que los conceptos analizados son para establecer un desarrollo evolutivo a futuro y conceptos del mundo virreinal como rey, vasallo, súbdito, buen gobierno y bien común serían centrales para comprender el imaginario virreinal. Teniendo en cuenta nuestra marcada pervivencia del mundo virreinal en los usos y costumbres, no sería importante evidenciar en los conceptos aquellos que resignifican el imaginario virreinal y lo validan en el mundo republicano. Estaba pensando en la noción de 
'pueblo' o si se pudo encontrar una relación entre 'súbdito' y 'ciudadano'. Otra pregunta necesaria es la pertinencia de los actores que enuncian los conceptos del corpus seleccionado, es decir, qué criterios validaron y qué actores políticos debían enunciar los conceptos seleccionados.

Debo mencionar la excelente decisión de ilustrar el libro con caricaturas políticas. Muchas evidencian verdades compartidas por la comunidad que las produjo y representan los mejores retratos del período estudiado. Sus narrativas visuales son los espejos más claros y descarnados de la opinión pública.

Reflexionar sobre los conceptos para entender nuestro paso a República nos permite pensar su vigencia. El libro constituye una consulta obligada para todos los peruanos, público general o estudioso. Para aquellos que entendemos que el Perú, más que una posibilidad como lo pensó el historiador Jorge Basadre, es una realidad. Para darnos sentido como país es necesario remitirnos a las ideas fundacionales. En vísperas de la celebración del bicentenario, este libro reflexivo sobre palabras claves del imaginario político republicano se hace imprescindible. La pertinencia del libro se justifica porque apela a la búsqueda de los conceptos para entender el imaginario político de los inicios republicanos y cómo estos continúan vigentes hasta la actualidad. No busca hacer una arqueología erudita para conocedores, sino que entiende que esos conceptos son importantes para comprender el devenir político presente. En tiempos de caída de paradigmas y de la crisis de ideologías, el libro propone regresar a los conceptos esenciales que estructuraron y dieron sentido a nuestro devenir contemporáneo y, por tanto, el libro se muestra como fundamental.

\section{Fernando Villegas Torres}

Universidad Nacional Mayor de San Marcos

Contacto: luis.villegas@unmsm.edu.pe

https://orcid.org/0000-0002-3899-240X 